\title{
A arte da pesquisa em artes: Traçando práxis e reflexão
}

\author{
Kathleen Coessens \\ (Vrije Universiteit Brussel, Instituto de Pesquisa em Música Orpheus)
}

\section{Introdução- Pensar o que estamos fazendo}

Alguns dados. Nem todos. Sem conclusões. Para quem me aceita são inúteis ambos. Os curiosos terão o prazer em descobrir minhas conclusões, confrontando a obra e os dados. Para quem me rejeita, é perda de tempo explicar o que, antes de ler, já não aceitou. ... Quando sinto a impulsão lírica, escrevo sem pensar em tudo que meu inconsciente me grita. Penso depois: não só para corrigir, como para justificar o que escrevi. Daí a razão deste Prefácio Interessantíssimo. (Andrade, 1968 [1922], p. 5).

A maneira que pensamos sobre as práticas da pesquisa está inserida nas tradições do ambiente de pesquisa, comunidades científicas, agendas e espaços de disciplinas compartilhados, e também, na nossa história, educação e no quadro ideológico ou visão de mundo que não só herdamos, mas também adotamos. Vivemos em um contexto de conhecimento em constante evolução e em uma sociedade informada, a qual requer articulação de práticas e experiências profissionais. Embora essa afirmação esteja implicitamente presente na construção da cultura ocidental do século passado (da qual a ciência e a arte foram, certamente, os resultados mais poderosos), ela ficou mais explícita, nos últimos dez anos, em todos os domínios culturais. A sociedade ocidental tem se tornado mais e mais focada em seus valores e produção epistêmica: mapeamos qualquer coisa como "conhecimento". As artes não escapam a essa evolução. Enquanto tal evolução tem benefícios, também tem os seus perigos. É claro que uma sociedade culturalmente e epistemicamente produtiva oferece potencial para práticas criativas e contribuições originais ao 
conhecimento. No entanto, quando renomeamos esta evolução como uma economia de conhecimento e os seus resultados como produtos, a pesquisa corre o risco de cair nas garras de um processo de comercialização e de racionalização, onde os valores estéticos e epistêmicos tornam-se econômicos.

O principal desafio da pesquisa artística é então, construir uma cultura de pesquisa que faça a diferença, tanto no campo da pesquisa, como na sociedade. Isso significa participar no campo mais amplo da pesquisa, mas a partir de sua própria perspectiva, por um lado resistindo à competitividade econômica, enquanto, por outro lado, representando valor para o desenvolvimento da cultura e da educação. O pesquisar artístico significa abrir um campo, até agora inexplorado, ou pelo menos que seja um campo não expresso, o que significa questionar as condições desse campo, incluindo o seu conteúdo e significado:

Para maior eficácia, a pesquisa artística precisa ser articulada em seus próprios termos, e não mediada através dos paradigmas mais dominantes da ciência - embora, como vimos, pode-se aprender com estes - e, especialmente, a partir das lições mais recentes que a própria ciência está aprendendo. (Coessens, Crispin e Douglas, 2009, p. 72).

Isso implica também em ter um compromisso com uma tarefa possivelmente comprometedora, mesclando arte e pesquisa em arte, criatividade e reflexão sobre ela, o ato de fazer e de conceituar.

O objetivo deste artigo é explorar o potencial da pesquisa artística como um campo experimental que beneficie nossa sociedade - artistas, pesquisadores e todos os outros públicos - de maneira que melhore a compreensão das práticas artísticas e o diálogo com outras culturas de pesquisa.

É somente através do artista que novas ideias sobre o conhecimento de outra maneira tácito e implícito podem ser adquiridas, e somente enquanto o artista/pesquisador permanecer um artista ele ou ela será capaz de enriquecer as pesquisas existentes realizadas por cientistas. (Coessens, Crispin e Douglas 2009, p. 91).

Tomando ferramentas ópticas como metáfora para maneiras de fazer pesquisa, eu mostrarei a riqueza da abordagem da pesquisa artística. Os binóculos, prismas e salas de espelho são três ferramentas óticas diferentes que revelam diferentes ângulos do objeto a ser investigado.

Na primeira parte, analisarei as diferenças entre uma visão binocular e uma visão 
prismática, e sua importância para a pesquisa. A pesquisa oferece sempre certo foco no mundo; ela "dramatiza" o mundo de maneira particular, trazendo seu próprio foco para o palco do conhecimento. Enquanto a visão binocular é mais presente na pesquisa, a investigação artística pode abri-la para uma visão prismática.

A segunda parte explora essas diferenças mais profundamente, através da análise das noções de experimento e de ação experimental, teoria e teorização. Ao oferecer esta polaridade, as posições são reforçadas.

A terceira parte irá considerar a complexidade da pesquisa do artista em sua própria prática artística. Uma situação em que o pesquisador é, ao mesmo tempo, sujeito e objeto, rompe claramente as regras da "objetividade" como um código de investigação estabelecida. A metáfora dos espelhos da sala octogonal de Leonardo da Vinci irá esclarecer a "centralização" e "descentralização" de tal atividade de pesquisa, decodificando as noções de reflexão e refletividade. Isso demonstrará a distância possível de um ponto de vista "subjetivo" e revelar o seu rico potencial.

Na quarta parte, ambas as preocupações da segunda e terceira parte se reúnem em uma análise da prática de pesquisa artística - que eu chamo de "rede de prática artística". Afirmo que a pesquisa artística sempre existiu, reconhecendo que, até recentemente, não foi institucionalizada. $\mathrm{O}$ artigo termina com uma pequena amostra de alguns exemplos avant la lettre, de ambos artistas europeus e brasileiros; isto irá articular e mostrar múltiplas perspectivas que a escrita e comunicação da pesquisa artística podem tomar.

\section{Sobre os binóculos e prismas, flaneurs e exploradores.}

A construção do objeto de estudo não é essencialmente metodológica no sentido de metodologia como ponto de partida epistemológico ou como procedimento de verificação. É estético, porque uma narrativa baseada em pesquisa dramatiza o mundo de uma maneira particular (Pelletier, 2009, p. 7-8).

As atividades do conhecimento são tributárias ao estado da arte predominante, às convenções sociais e intradisciplinares, e às regras feitas pelo homem. $O$ conhecimento disponível e sua comunidade de pesquisa vigente determinam o espaço de perguntas e respostas, interpretações e representações que podem aparecer, e quais permanecem não só desconhecidas, mas também inaceitáveis por 
(Rescher 1999). Diferentes nichos intelectuais e disciplinares - diferentes ao longo do tempo e do espaço - decidem sobre o que conta como conhecimento, mais ainda, o que é desejável como conhecimento. Embora a cultura global de pesquisa tenha características diferentes para compartilhar - como semelhanças de família no sentido de Wittgenstein - todas elas usam seus próprios binóculos para se concentrarem em uma determinada direção e orientação, e esclarecer uma parte específica do que é tão difícil de distinguir do ruído de fundo. Pense em física ou química: eles começam a partir do mesmo mundo, mas usam um binóculo diferente para divulgar dois lados divergentes deste mesmo mundo. Além disso, suas práticas e métodos subjacentes são desenvolvidos para sustentar esse foco particular.

A arte não olha para o mundo através de binóculos, mas sim através de um prisma. O prisma é um objeto óptico transparente com superfícies planas e polidas que refratam a luz ou a fragmentam em suas cores espectrais constituintes, dependendo do ângulo e dispersão das superfícies. O artista sempre voltou sua atenção para ângulos do mundo diferentes, muitas vezes inesperados, resistindo não apenas ao óbvio, mas também ao foco disciplinar - forçando o olhar a partir de certo ângulo:

Os artistas, como os etnógrafos, treinam seus olhos para verem coisas que outras pessoas não veem. Eles tentam apresentar o que eles veem para que nós, o público, possamos vislumbrar algo aonde olhamos milhares de vezes e não conseguimos encontrar nada notável (Hoyem, 2009).

O artista é como o flaneur de Baudelaire e de Benjamin, presente no interior do estressado tempo urbano e das necessidades econômicas, mas tendo a capacidade de apreciar todos os lados do prisma. É um tipo de pessoa que surgiu no século XIX, como a que resistiu ao estresse e as pressões econômicas da modernidade. $\mathrm{O}$ flaneur observa, funde-se com a multidão, tendo ainda seus próprios pensamentos e ritmo, absorvendo seus ruídos, cores, caos, heterogeneidade, o seu cosmopolitismo (Hess 2009). O flaneur está no meio da multiplicidade de camadas, andamentos e ritmos diferentes, e ao mesmo tempo, escapa do tempo e estruturas de espaço impostos, cultivando, como Balzac disse, a gastronomia do olho - Eu diria que para o artista, a gastronomia dos sentidos. No entanto, o flaneur e em analogia ao artista, não é apenas um andarilho e observador do mundo exterior, mas também do próprio interior, do próprio pensamento e da imaginação, criando diálogo e tensões entre o sujeito e as ações. Tanto o artista, quanto o flaneur 
resistem à tentação da ideologia dominante - a cidade ou a economia do conhecimento -, e desenvolve outras perspectivas.

Para o flaneur, é um modo de vida e de observação, enquanto que para o artista vai mais longe: todas as perspectivas sensoriais oferecem diferentes encontros estéticos e possíveis fontes de criação. A experiência do artista segue caminhos diferentes no tempo e no espaço, na percepção e na criação, e incorpora um campo rizomático de trajetórias. Esses continuam, muitas vezes, inexplorados, como o artista, após a criação, retira-se de uma investigação de sua prática e deixa o objeto artístico como traço único.

É aqui, nesses interstícios inexplorados da prática artística, que a pesquisa artística pode entrar em cena. Percursos vivenciais e experimentais só podem ser salvos do esquecimento pelo empenho do artista na exploração e expressão dos diferentes caminhos e traços de sua prática - pelo artista como pesquisador. A visão e a iniciativa são novamente prismáticas, mas os diversos reflexos coloridos são agora objetos de preocupação estética e epistêmica. Esse empreendimento abre caminhos de pesquisa que podem trazer novos conhecimentos, bem como alterar 0 conhecimento existente.

Isso significa que o pesquisador artista tem que ser mais do que um flaneur, ele tem que ser um explorador, determinado a investigar, em profundidade, tanto o terreno desconhecido, quanto as práticas próprias. "Explorar" significa "investigar, procurar, analisar", mas na origem do latim também significa explorare, ou seja, "gritar, intervir". ${ }^{1}$ De um lado, a exploração de diferentes especialidades, métodos, práticas e questões, nas ciências naturais, humanas e cognitivas, em relação com o campo das artes, lançarão uma espécie de fórum para o diálogo e a reflexão sobre o conhecimento-criação, descoberta e investigação. Do um outro lado, a idiossincrasia e a abertura prismática das práticas artísticas, instigam o artista-pesquisador a desenvolver suas próprias maneiras de experimentação e exploração. O artistapesquisador, assim como o artista, tem uma visão prismática, diferente da binocular.

\footnotetext{
${ }^{1}$ Meu colega Fernando Iazzetta chamou minha atenção para esta última conexão etimológica.
} 


\section{Experiência, experimento, exploração.}

... nenhuma produção de conhecimento nas ciências humanas pode jamais ignorar ou negar o envolvimento de seu autor, enquanto um sujeito humano, em suas próprias circunstâncias. (Said, 1978, p. 11).

A revolução científica europeia no final do século XVII abriu um novo caminho para o conhecimento: ciência, experimentação e método científico. A prioridade foi dada ao intelecto e seus possíveis processos de objetivação extraídos da informação empírica, enquanto outras abordagens mais perceptivas e/ou intuitivas foram mais ou menos ignoradas, pelo menos na comunidade científica que foi construída.

Esta abordagem pode ser chamada de uma abordagem cognitiva, que privilegia a abstração e a objetividade distanciada, a partir de uma "hipótese", a qual tornou-se a forma predominante de construção do conhecimento da comunidade científica. A pesquisa, então, seria conduzida por um pensamento "intencional", onde a ênfase na construção do conhecimento "sobre" algo definitivamente externa ao pesquisador cria uma distância entre sujeito e objeto. É a experimentação desenvolvida como um objetivo bem definido, a montagem do laboratório limpo, com o objetivo de ganhar um pouco mais de conhecimento no já vasto domínio do conhecimento.

Na ciência ocidental e na construção do conhecimento, perspectivas de orientação teórica claramente ofuscaram as perspectivas orientadas pela experiência: o binóculo ofuscou o prisma. Assim, uma abordagem estética foi deixada de lado. Estética quer dizer aqui, no puro sentido da palavra "sentidos", também sobre o ponto de vista experiencial. Em tal abordagem estética, a pesquisa tem origem em um "pensamento testemunho", um pensamento a partir de uma experiência: "uma forma de interação reflexiva que envolve a nossa entrada de contato com seres vivos (ou em movimento) não familiares" (Shotter, 2005, p. 145-6).

Enquanto a abordagem orientada pela teoria tornou-se o método científico dominante, a abordagem orientada pela experiência foi favorecida pelas formas de compreensão do mundo "não científicas" ou artísticas. No entanto, ambas as perspectivas visam um questionamento do mundo, resultando em uma melhor compreensão dos seres humanos e de seu meio ambiente, e em conhecimento que pode ser comunicado: 
Os dois domínios moldam a cultura em seus próprios modos. Ambos se originam do mesmo mundo e suas manipulações, transformações e conquistas partilham da mesma natureza humana. Seus domínios de origem são, portanto, equivalentes. Ambos têm de começar a partir das restrições do mundo e das limitações do ser humano, ambos têm de lidar com o contexto cultural e convenções vigentes. Mas os processos reconstrutivos e objetivos da prática científica e artística são diferentes. Seus domínios alvo apontam para mundos diferentes. No caso da ciência, o objetivo do esforço é limitado pelas restrições de situações do mundo real, no caso da arte, este objetivo é apenas limitado pelas restrições da imaginação humana. Isto implica que o horizonte de possíveis significados da arte é muito mais indeterminado do que na ciência. (Coessens, Crispin \& Douglas, 2009, p. 25-6).

Como se observou, a própria noção de experimentação seguiu esta orientação divergente. Enquanto que na ciência, o experimento segue um padrão de ação bastante instrutivo e protocolado, ligados às experiências anteriores e a seu status dentro do conhecimento científico, nas artes, o experimento está ainda embutido nos aspectos inesperados e na improvisação de uma prática artística. Como o compositor John Cage escreveu: "uma ação experimental é aquela cujo resultado não está previsto" (1961, p. 39).

A noção de ação é interessante nas artes, uma vez que coloca o experimento dentro de uma relação sujeito-ambiente. Uma ação experimental é baseada na observação e intervenção, explorando as relações desconhecidas entre o sujeito e a ação. Não é apenas sobre "o que acontece", mas sobre a própria ação que faz "o que acontece" e a possível intervenção. A experimentação aqui está muito mais relacionada às suas origens etimológicas de risco e perigo. A palavra experiência tem origem do verbo latino periri, que significa "experimentar", mas também "correr riscos" e até "morrer" - pensar em perigo. O prefixo ex implica um movimento, um "sair".

Outra diferença que é notável entre uma abordagem de pesquisa artística e outras disciplinas de pesquisa é a noção de teoria. Diferentes campos de pesquisa e de suas práticas experimentais são conduzidos por teorias estabelecidas bastante férteis; elas são baseadas em tais teorias, mesmo que os experimentos possam levar a uma revisão da teoria em si. No entanto, no domínio das artes, as teorias não podem ser articuladas de forma isolada da prática e da pesquisa do artista, porque elas são estabelecidas e construídas a partir da própria prática. E essa prática em particular contém uma busca inesperada e de caráter aberto, constituindo assim um resultado criativo e estético. A criatividade não pode emergir de dentro das 
paredes que protegem uma teoria, ela tem que ser descoberta nas fissuras, nas lacunas, no que falta ao inexplorado, em resumo, o artista tem que procurar a diferença, não para a continuidade - mesmo que essa diferença possa estar dentro de uma continuidade. Como tal, o artista utiliza diversos tipos de conhecimento, uma bricolagem epistêmica de experiências e conhecimentos a respeito do corpo, materiais, inspirações pessoais, além do contexto cultural em que ele se insere (LéviStrauss 1962). Na arte e na pesquisa artística, devemos considerar o ato de teorizar, em vez de investigar a partir de uma teoria reconhecida:

Enquanto teorizando, então, pode ser brincalhão e cheio de movimento, a teoria significa o congelamento de um conjunto de pensamentos. (...) Teorização (...) significa uma tentativa de compreender e explicar (...) e inclui tudo o que antecede a formulação final que é definida no papel ou fixa de alguma outra forma ("teoria"). Isso significa interação com as pessoas e os textos, como livros e artigos, entre outras coisas. (...) A intuição, imaginação e abdução também são indispensáveis para a teorização de sucesso. (Swedberg, 2012, p. 15).

As conexões entre os passos que um artista toma, a reflexão sobre a própria prática e as suas trajetórias, seus materiais, seu conhecimento oculto, bem como as muitas vezes implícitas - relações com outras artes e em um contexto mais amplo, formam uma espécie de método, uma maneira de fazer que então gera o próprio "conhecimento artístico". Elas revelam uma atitude de teorização: desvendando esses processos por reflexão, análise, explicação, conceituação, mas também por questionamento, brincadeiras, experiências e através do aprofundamento da visão e da estética e contextos epistêmicos e estéticos em torno do próprio processo artístico. No entanto, isso não é um processo simples de teoria. A dificuldade surge em como coletar a descontinuidade e justaposição de conhecimento(s) em uma totalidade coerente ou pelo menos compreensível para que possa ser comunicável à sociedade. Um uso centrado do artista e intervencionista do conhecimento oferece novas perspectivas, mas pode ser menos acessível do que a abordagem de um pesquisador tradicional, que se esforça para a continuidade do quadro de conhecimento, teoria e conteúdo, bem como por um ponto de vista centrado no leitor. Isso sugere frequentemente provocação e investigação de caráter aberto por um lado, integração e foco por outro.

\section{Práxis e reflexão na rede da prática artística}

O eu passa a existir no momento em que possui o poder de refletir sobre si mesmo. (Douglas R. Hofstadter, 1980, p. 709).

Voltando ao prisma da abordagem artística, precisamos adicionar outra ferramenta 
visual estendida, que ajuda a entender os desafios da pesquisa artística e, mais precisamente, apreciar as múltiplas faces da sua abordagem centrada no sujeito: a sala de espelhos.

Em um de seus manuscritos, Leonardo da Vinci descreve uma invenção interessante: uma sala octogonal composta de oito espelhos retangulares. Entrando naquela sala, um sujeito é confrontado com a visão de si mesmo em um número infinito de vezes a partir de diferentes ângulos. A reflexão oferece perspectivas sensorialmente impossíveis sobre o seu corpo, as perspectivas que nunca são atingíveis sem este tipo de ambiente. Ele permite uma experiência multissensorial de auto-exibição.

Estas reflexões do espelho criam, em primeiro lugar, uma exteriorização e "exposição" do corpo - do eu - a qual normalmente desconhecemos, levando a uma situação preocupante. Esta situação do corpo estendido é preocupante ao nível visual e cinético da percepção. Cineticamente, ele perturba o esquema corporal habitual de ação, como o movimento e a percepção, adicionando experiências totalmente novas. Essa relação entre o movimento e a percepção parece apenas controlável: movendo a frente do corpo de forma coerente com a sua reflexão, estendendo-se também as habilidades motoras e sensoriais. Além disso, no plano visual, o ator diante do espelho pode experimentar o que é normalmente reservado para outras pessoas - vendo os seus lados, costas, e movimentos.

Em segundo lugar e partindo deste exemplo, o experimento salienta o problema dos limites do corpo, sua centralidade, bem como a sua abundância no meio ambiente. A extensão do corpo é dependente de sua relação sensorial e cinética com o meio ambiente. Normalmente, essa relação começa a partir de uma posição centralizada, tanto do corpo, quanto do eu. No entanto, aqui está redefinido pelos parâmetros de extensão visual e de movimento. À medida que a percepção interior do corpo está descentrada, o corpo é experimentado a partir do interior, bem como do lado de fora: por onde ele começa e até onde ele termina? A reflexão oferecida pelo ambiente leva o sujeito a uma reflexão sobre o seu próprio corpo, à sua aparência, extensão, e exibição.

Há uma analogia entre o reflexo no quarto de espelhos octogonais de da Vinci e a 
reflexão sobre a própria prática artística. Em primeiro lugar, com a indagação sobre o próprio processo artístico, trajetórias, significado e contexto, aspectos ocultos são revelados, por vezes perturbadores e às vezes até inesperados. O que estava oculto na experiência da própria criação, além do objeto de arte, revela-se pela investigação e reflexão. Em segundo lugar, e na sequência, a posição do artista e a obra de arte são descentralizadas, pois o artista como pesquisador enfoca tanto o sujeito, como o objeto, complementando uma criação idiossincrática subjetiva distanciada, mas ainda envolvendo a reflexividade. Como é que eu cheguei lá? Quais foram às implicações desse ato? De onde veio essa influência? Em analogia, com a multiplicação das possibilidades performativas em uma sala de espelho, o artista-pesquisador desvenda uma diversidade de auto-referenciais, contextuais e de sabedorias implícitas que se relacionam com o corpo e os sentidos, em um contexto privado ou público ou na imaginação. O reflexo do espelho torna-se a reflexividade do pesquisador, uma consciência profunda da relação única, dinâmica e pessoal, onde ele se encontra envolvido com o exterior. Quando a reflexão é dada pelo lado de fora do espelho, a reflexividade é o salto de fora do que acontece com o sujeito - reflexão - o seu compromisso de ser e de agir nesse mundo. Um círculo se desenrola entre o dentro e o fora, criando um laço entre fazer e pensar, ator e espectador, deixando vestígios de reflexão e reflexividade.

Não há mais o original e o derivado; existe um pensamento que se move em um círculo onde a condição e o condicionado, a reflexão e o refletido, encontram-se em uma relação de reciprocidade, e onde o fim é o começo, como o princípio é o fim (Merleau-Ponty, 1968, p. vi; 35).

Como tal, além do rastreamento do objeto artístico ou manifestação, o artista-pesquisador explora um processo complexo de ação e reflexão, de decisão e criação, revelando partes e parcelas da ampla rede de prática artística. Esta rede é tecida ao longo do tempo e do espaço e é composta por diferentes dimensões tácitas - tácitas porque elas estão presentes no fundo do ato criativo do artista (Coessens 2013).

O primeiro destes é a dimensão encarnada. Os artistas têm uma relação específica com o corpo, a moldagem e treinam isso para atingir o conhecimento em cinestética, coordenação motora-sensorial e intelectual. O corpo está bem afinado para as ações, materiais, ferramentas, instrumentos - em um tipo de atividade unificada em que as qualidades e as sensações vêm juntas. O corpo do artista é o 
seu primeiro meio de expressão. Cada ato de criação artística envolve o corpo de maneiras específicas, e exige um envolvimento elevado do corpo.

A segunda dimensão é o conhecimento pessoal do artista, pelo qual é inevitavelmente determinado e envolvido no fundo ambiental ou contextual. 0 artista participa de um sistema de conviç̧ões, paixões intelectuais, compartilhando uma "rede de crença" (Quine 1953/1970), com uma comunidade com a mesma opinião. Nessa rede de crenças de uma pessoa, a entrada das gerações anteriores, ideias culturais, tecnologia, educação e ciência, mas também a identidade pessoal, lembranças e compromisso se fundem em uma ação presente: "As tradições nos são transmitidas do passado, mas são as nossas próprias interpretações do passado, em que chegamos dentro do contexto de nossos próprios problemas imediatos" (Polanyi 1958, p. 160). Muito desse conhecimento pessoal permanece tácito, desarticulado e no fundo de nossos atos.

Uma terceira dimensão é o ambiente ecológico. O espaço circundante, as suas dimensões, cores, a incidência de luz, a temperatura e o grau de umidade ou até mesmo a mobília terá alguma influência ou impacto na prática do artista. Um músico, por exemplo, irá repetidamente ajustar-se ao espaço circundante com as suas próprias características acústicas, suas dimensões, cores, móveis, ar, temperatura, pessoas presentes, bem como os instrumentos de outros músicos. Um pintor será confrontado com a luz predominante, as alterações sazonais, os tons das tintas de cores disponíveis. Mais tarde, as condições de luz e o posicionamento da pintura na sala de museu irão influenciar o seu brilho e a percepção do mesmo por parte do público. O ambiente, com seus materiais e as leis, sempre vão influenciar o artista e sua criação, em alguma direção.

A quarta dimensão refere-se às possibilidades culturais para a arte: as ferramentas, as linguagens, os códigos que permitem ao artista traduzir seu pensamento criativo e atuar em algo durável. Diferentes meios de comunicação e sistemas de sinais (semiótica) possibilitam a descoberta, tradução, transmissão, interpretação e gravação de arte. Os sistemas semióticos estão profundamente enraizados nos estilos socioculturais, valores e significados, bem como ligados à evolução tecnológica. Eles oferecem liberdade e restrições. As respostas e criações artísticas, 
mesmo resistentes ou subversivas, terão que lidar com estes, usá-los, transgredilos, transformá-los, e inová-los.

A última dimensão nos traz de volta a auto-reflexividade. Esta dimensão é o reino da interação discursiva humana, sendo em diálogo ou em monólogo: todo o tipo de encontro com o outro, seja o outro artista ou a comunidade de artistas, o ouvinte ou a audiência, pública, sociedade, críticos, amigos e parentes, ou, por último, mas não menos importante, o próprio artista imerso no processo criativo. Esta dimensão move a ação e a pesquisa da reflexão à reflexividade, de consciência de responsabilidade cometida, como menciona Sandywell: "a reflexão trata o Outro como uma ocasião para consolidar o Eu, a reflexividade aborda o Outro como um sinal para o movimento irredutível do diálogo e da espontaneidade no âmbito da individualidade" (1996, p. 5).

De um lado, seguindo Sandywell, a reflexividade é considerada como a consciência e a experiência de si mesmo, como uma participação numa prática concreta que implica uma antecipação de reflexão. De pé na prática significa estar envolvido, envolvido em uma situação de intencionalidade afetiva e epistêmica, ao ser envolvido em uma tradição, um antecedente. Do outro lado, é também a experiência da diferença e da dissonância, o encontro dentro de cada projeto de construção do mundo de alteridade e violência, questionando todas as práticas humanas e significado, e forçando o indivíduo a estratégias e táticas (Sandywell, 1996, p. 5; de Certeau, 1980). Há uma clara ligação aqui com a atitude de exploração de flaneur de Baudelaire.

Como cada rede de prática do artista nunca termina, o esforço artístico continua a ser um processo dinâmico em que o artista terá que reajustar os esquemas anteriormente adquiridos, cada vez (re)-criando sua arte, reconstruindo sua rede. 0 artista terá que lidar, outra vez, com aspectos novos ou diferentes daquelas de dimensões tácitas, cada vez explorando novas situações, adaptando e reajustando suas habilidades e competências ligeiramente diferentes dos parâmetros internos e externos - habilidades incorporadas, conhecimento pessoal, códigos semióticos, meio ambientes, auto- reflexividade e da presença dos outros. O artista pesquisador pode então desvendar certos aspectos destas dimensões tácitas: por exemplo, explorar gesto e 
incorporar o conhecimento por trás do ato artístico; investigar o fundo intelectual, artístico e ramificações da criação; traçar a transformação de sinais e símbolos tradicionais em linguagem do artista; analisar o impacto e o papel do ambiente ecológico. O artista-pesquisador pode combinar diferentes dimensões, mas sempre abordará estes a partir do ponto de vista da própria criação, do eu, do artista. A pesquisa artística então, sendo prismática e reflexiva, vai construir um conhecimento caleidoscópico, explorando partes e parcelas a partir da rede artística do conhecimento.

\section{Rastreamento da exploração para a expressão}

Estou plenamente consciente de que o fato de não ser um homem de letras pode fazer com que certas pessoas arrogantes pensem que elas podem, com razão, censurar-me, alegando que eu sou um homem ignorante do aprendizado literário. (...) Eles dirão que, por conta da minha falta de aprendizado literário, eu não posso me expressar adequadamente. Será que eles não sabem que os meus temas exigem para sua exposição a experiência, em vez de palavras de outras pessoas? (...) As minhas conclusões foram obtidas como resultado da experiência simples e pura, o que é a verdadeira paixão (da Vinci, 1955, p. 57-58).

Voltando 500 anos, Leonardo da Vinci manteve cadernos de sua pesquisa em ciências e artes. Seus livros eram cheios de desenhos e diagramas, explicados com notas escritas invertidas (vistas somente com um espelho). Ele se comprometeu, por exemplo, a estudos detalhados sobre óptica e a investigação de espelhos. Ele combinou uma estética e fascínio científico para tudo o que poderia ser investigado de forma criativa. Em seus cadernos, ele analisou a geometria abstrata presente nos padrões de reflexão e a utilidade potencial de espelhos côncavos como fontes de calor. Esses recursos e experiências de pesquisa ofereciam trajetórias através de sua imaginação, conhecimento e arte.

Da Vinci mostrou que, enquanto a pesquisa artística é um campo emergente da cultura de pesquisa institucionalizada, exemplares avant la lettre, ou seja, antes do advento da institucionalização, são múltiplas e diversas. Este artigo começou propositadamente com outro exemplar: a citação do Prefácio Interessantíssimo do brasileiro Mario de Andrade, que, no início do século XX, escreveu um volume de versos revolucionários sobre a cidade de São Paulo, no final do ano de 1910, "Paulicéia desvairada "ou" Hallucinated City". Ele acompanhou essa poesia com o que ele chamou de um "Prefácio interessantíssimo", em que ele analisou seus 
próprios processos de criação, bem como a sua contextualização na poesia de vanguarda no Brasil e nos movimentos modernistas mais amplos da Europa. Mais tarde, ele mesmo reelaboraria essas ideias de "investigação artística" em uma reflexão mais profunda sobre a natureza da composição da poesia lírica no século 20 - em A Escrava, que não é a Isaura, com o subtítulo Um Discurso sobre algumas tendências em Poesia Modernista - e indagar sobre o que ele considerava os principais constituintes da criação poética: o papel do ato de inspiração e o ato de crítica (Suarez \& Tomlins 2000, p. 19; 46).

Vamos viajar através de alguns outros exemplos.

É final do século $X X$, o reino imaginativo e do som do instrumento acústico parecem estar exaustos. No entanto, o compositor experimental contemporâneo, Helmut Lachenmann, propõe um mundo novo do som. A obra temA para flauta, voz e violoncelo (1968) explora de uma forma muito direta, o ato físico e o esforço da respiração, uma experiência de vida afirmada e restrita. Como podemos respirar quando dormimos, quando em esforço, quando na dor? A respiração é normalmente um processo tácito, que faz parte da fisicalidade humana. Ao mesmo tempo, é um processo energético acusticamente mediado na base da voz humana e de todos os instrumentos de sopro.

Juntamente com temA [para flauta, voz e violoncelo] e Pression para violoncelo solo, Air [para percussão solo e orquestra] representa na minha produção a ruptura consciente com os hábitos sócio estéticos estabelecidos: a tentativa e a proposta do Belo não só através da recusa do habitual, mas também pelo desmascaramento das condições que validam o Belo: como repressão dos condicionalismos fisiológicos e das energias físicas que the subjazem, repressão do esforço implícito-se quisermos: do trabalho escondido por trás do Belo (Lachenmann 1996[1973], p. 102). ${ }^{2}$

Pesquisando artisticamente as possibilidades extremas de instrumentos acústicos, Lachenmann também traçou sua visão sobre a música e o som no livro Musik as existentielle Erfahrung. Podemos agora compreender algumas das necessidades, dos motivos e do conhecimento por trás de sua música.

Na primeira metade do século XX, Paul Klee elaborou suas palestras Bauhaus, investigando

2 Zusammen mit temA und Pression für Cello solo bedeutet Air in meinem Schaffen den be- wußten Einbruch in gesellschaftlich-ästhetische Selbstverständlichkeiten: den Versuch und das Angebot von Schönheit nicht allein durch Verweigerung des Gewohnten, sondern durch Ent- larvung der Bedingungen von geltender Schönheit: als Unterdrückung von zugrundeliegenden physikalischen Voraussetzungen und physischen Energien, Unterdrückung der zugrunde- liegenden Anstrengung; wenn man so will: der dahinter verborgenen Arbeit (Lachenmann 1996 [1973], p. 102). 
sobre desenho e movimento. Em seu caderno de desenho pedagógico, começou a partir do desenho de ponto, mudando para uma linha e depois para uma forma geométrica ou para as forças naturais. O desenho tornou-se uma narrativa ou uma trajetória, um caminho imaginário através da força e da atração, necessidade e contingência. O movimento se torna parte da arte e parte da vida.

Em primeiro lugar, o que queremos dizer com movimento na obra? Como regra nossas obras não se movem. Afinal de contas, nós não somos uma fábrica de robôs.

Não, nelas mesmas, nossas obras, ou a maioria delas, ficam sem sair do lugar, e ainda assim estão todas em movimento. $\mathrm{O}$ movimento é inerente a todas elas, e antes de a obra ser, ela deve se tornar, assim como o mundo tornou-se antes que fosse, após as palavras: "No princípio, Deus criou", e deve continuar a tornar-se antes de ser no futuro (Klee, 1961, p. 355).

$\mathrm{Na}$ exploração de Klee, as intricadas relações entre o gesto artístico e o movimento humano, a arte e a filosofia oferecem um caminho para a criação e o pensamento.

O escritor Italo Calvino escreveu o maravilhoso livro Cidades Invisíveis, narrando o diálogo entre o imperador Kublai Kan e aventureiro Marco Polo. A narrativa se baseia na imaginação materializada e perceptual, emergindo da interação entre o ser humano e o meio ambiente.

(...) A minha escrita sempre esteve diante de dois caminhos divergentes que correspondem a dois tipos diferentes de conhecimento. Um caminho vai para o espaço mental da racionalidade sem corpo, onde se podem traçar linhas que convergem, projeções, formas abstratas, vetores de força. O outro caminho passa por um espaço repleto de objetos e tentativas de criar um equivalente verbal daquele espaço enchendo a página com palavras, envolvendo um esforço meticuloso e cuidadoso para adaptar o que está escrito para o que não está escrito, para a soma do que é dizível e não dizível. Estes são dois caminhos diferentes em relação à exatidão que nunca atingirá sua realização integral (Calvino 1996, p. 100).

Sob a produção artística ele refletiu sobre as interações entre a literatura e a vida e sobre o seu próprio processo criativo em seis memorandos para o próximo milênio. Cada 'memo', respectivamente em leveza, rapidez, exatidão, visibilidade, e multiplicidade oferece uma visão sobre a vida e a criatividade.

A partir dos vinte anos, Sergei Eisenstein, notável cineasta na Rússia, refletiu sobre a produção de filmes, mas também sobre as tensões com a política, com o público e com os seus próprios impulsos artísticos. Seus escritos foram agrupados em três livros, um compêndio de seus trabalhos Selecionados, em grande parte, em forma de rascunho. Eles mostram um homem lutando com as suas próprias retóricas 
ideológicas, mas também um artista que reflete sobre 0 impacto e 0 desenvolvimento da tecnologia em sua própria estética de filme. A vinda do som sincronizado, as possibilidades de montagem desafiam sua ideia original da justaposição de elementos significantes. A Montagem para Eisenstein é um poderoso princípio humano presente em todas as atividades da arte, e implica a espacialidade da representação e da temporalidade da poesia (Nowell-Smith, 1991, p. xv).

Eu sempre me preocupei mais com o movimento - movimentos de massa, movimentos sociais, movimento dramático - e meu interesse criativo sempre foi mais intensamente direcionado para o próprio movimento, em direção às ações e obras enquanto tais, em vez de para a pessoa as executando. (...)

No final, devemos considerar a noção de que o homem, sua consciência e atividade, não é somente a base do que é expresso no conteúdo de um filme, mas aquele homem também se reflete nas exigências da forma e das leis estruturais da uma obra de arte (Eisenstein, 1991, p. 1;4).

Ao lado da arte que criaram, esses artistas tiveram a necessidade de descrever, explicar como eles trabalharam o que eles queriam dizer em suas obras de arte, ou apenas que tipo de conhecimento eles usaram - como Leonardo da Vinci fez em seus cadernos, explicando o conhecimento científico que sustentava sua criação artística, ou como o compositor Helmut Lachenmann que investigou os limites de possibilidades sonoras dos instrumentos acústicos e do corpo. Seis abordagens diferentes, seis abordagens que se estendem a criação artística em uma investigação artística sobre os processos daquela criação e de seu contexto. Eles são exemplos de como algum conhecimento artístico implícito da criação e do contexto por trás de uma obra de arte pode ser divulgado e expresso. Os exemplares estão em linguagem escrita, no entanto, devemos reconhecer que muitos envolvem materiais visuais - (como Klee, Eisenstein e Da Vinci); iniciavamse na matéria poética artística (como de Andrade) ou sequer foram incorporados em palestras ou na transmissão pedagógica (como Klee, Eisenstein e Lachenmann).

Nos exemplares anteriores de avant la lettre foram oferecidos diferentes formas de se compartilhar a pesquisa artística. Não há nenhuma maneira garantida de se transformar ou traduzir uma prática em um discurso, algo feito em um escrito. No entanto, diferentes perspectivas, traduções e discursos podem desvendar alguns dos mistérios de processos e práticas. A escrita é outra característica de diferentes culturas de investigação. Enquanto que a pesquisa acadêmica é centrada no leitor, 
sobre a experiência e relacionados ao discurso, na pesquisa artística é bastante centrada no artista, dentro da experiência e com base na prática. Escrevendo sobre e na pesquisa artística, como tal tem o seu potencial e as suas falhas: coisas que podem encontrar uma expressão escrita, e outras que não podem. As tensões sobre o que pode e o que não pode ser expresso a partir de um domínio para outro, envolve o artista pesquisador avançar e recuar entre os dois, constantemente revisando as duas línguas e repensando o próprio processo de heurística:

Longe de ser uma questão de privilegiar o texto escrito em vez da construção visual ou abolir o mesmo por completo, (...) a experiência dos artistas/pesquisadores mostra que as duas formas são integrais. 0 elemento de escrita também foi percebido como tendo adicionado uma profundidade, percepção e dimensão maiores ao processo de investigação. (Macleod e Holdridge, 2004, p. 157).

O processo de escrita pode ser uma das faces, um dos espelhos de reflexão e de reflexividade, lançando alguma luz sobre as camadas epistêmica e estética da arte. A pesquisa artística necessita de observação, experimentação e comunicação de seus tópicos e práticas. As relações experimentais ocorrem não só dentro de práticas artísticas, mas também no plano interacional onde o mundo sensorial, criativo e estético do artista encontram o mundo da ciência, investigação e de comunicação explícita. Embora as diferentes linguagens artísticas sejam o domínio preferido dos artistas, a pesquisa artística visa à participação de um discurso de pesquisa mais amplo e, inevitavelmente, precisa de envolvimento em uma ou outra maneira com a cultura verbal, não descartando outras formas de expressão. Portanto, o livro do artista-pesquisador, pode existir nas interseções do visual e do auditivo, da fotografia e da poesia, da narrativa experimental e das artes visuais, do desempenho e da transmissão.

\section{Conclusão}

O que se sabe é esmagadoramente determinado pela maneira que é conhecido. Explorar e expressar uma cultura de pesquisa artística é enriquecer o conhecimento e remodelar determinadas maneiras experimentais que o conhecimento tomava desde há muito. Tal maneira de produção de conhecimento oferece, como já mencionado, uma resistência à relação sujeito-objeto distanciada.

O que acontece quando um intérprete de música de repente comenta: Eu sei que há 
esta partitura, com todas as suas análises melódicas e harmônicas, com toda a tradição musical explicada por musicólogos, em instituições e em textos; Eu sei que há o som, as gravações e a ideia estética do compositor que eu tenho que expressar através do meu desempenho, mas e sobre o meu processo artístico, e o que dizer de minha narrativa e trajetória, meu corpo, o que acontece com todos os meus ensaios e desempenho relacionados às preocupações e processos o qual não somente entendo, mas totalmente revelam esta música? O que acontece quando um artista visual explora explicitamente o caminho de um ponto que se transforma em uma linha, ou em uma forma? E quando um artista tenta descobrir as condições que permitam fazer arte, e que refletem sobre os constrangimentos e a liberdade, sobre o impacto do campo e da sociedade sobre sua prática artística? O que acontece quando, o que um artista faz, pensa, ou como um artista age não é tópico de nenhum outro pesquisador, mas um processo de autorreflexão, possibilitando a melhoria da própria obra, expressando e explicando esses processos ao mesmo tempo que revelando algum conhecimento novo para os outros? Neste caso, um artista é também um pesquisador-artista, traçando sua práxis e reflexão. 


\section{Referências}

ANDRADE, Mario de. Pauliceia Desvairada (Hallucinated city), trans. by J.E. Tomlins, Nashville, Tennessee: Vanderbilt University Press, 1968. Veja também http://www.mac.usp.br/mac/templates/projetos/jogo/pauliceia.asp. Acessado em 03 de Abril de 2013.

CAGE, John. Silence. Middletown: Wesleylan University Press, 1961.

CALVINO, Italo. Six Memos for the Next Millennium. London: Feedbooks, 1988.

COESSENS, Kathleen, Anne Douglas, and Darla Crispin (2009) The Artistic Turn: A Manifesto, Orpheus Research Centre in Music Series, 1, Leuven: Leuven University Press.

DA VINCI, Leonardo. The notebooks of Leonardo Da Vinci - arranged, rendered into English and Introduced by Edward MacCurdy. New York: George Braziller, 1955.

DE CERTEAU, Michel. L'invention du quotidien 1. Arts de faire. Paris: GALLIMARD, 1980.

EISENSTEIN, Sergei. Selected Works Volume II - Towards a Theory of Montage. London: BFI Publishing, 1991.

HESS, Charlotte. Penser, c'est se déplacer. Vers une flânerie, comme pensée en acte, In: Liandrat-Guigues, Suzanne. (Dir.), Propos sur la flânerie. Paris:

I'Harmattan, 2009.

HOFSTADTER, Douglas R. Gödel, Escher, Bach. New York: Basic Books, 1980.

HOYEM, Martin. This, upon reading The Americans (Book Review). American Ethnography Quasimonthly, 2009.

http://www.americanethnography.com/article.php?id=71\#.ULJwG0JBDnl, Acessado em 20 de Novembro de 2012.

KLEE, Paul. Notebooks Volume 1 - The thinking eye, London: Percy Lund, Humphries \& Co., 1961.

LACHENMANN, Helmut. Die gefährdete Kommunikation. In: Musik als existentielle Erfahrung. Wiesbaden: Breitkopf \& Härtel, 1996 [1973].

LÉVI-STRAUSS, Claude. La Pensée sauvage, Paris: Librarie Plon, 1962.

MACLEOD, Katy and HOLDRIDGE, Lin. The Doctorate in Fine Art: The Importance of Exemplars to the Research Culture. International Journal of Art \& Design Education n. 23 v. 2, p. 155-168, 2004.

MERLEAU-PONTY, Maurice. The phenomenology of perception, Trans. C. Smith. London: Routledge and Kegan Paul, 1945/1962.

NOWELL-SMITH, Geoffrey. Eisenstein on Montage, In: Sergei Eisenstein, Selected Works Volume II - Towards a Theory of Montage. London: BFI Publishing, 1991. 
PELLETIER, Caroline. Rancière and the poetics of the social sciences. International Journal of Research and Method in Education, v. 32, n. 3, p. 267-284, 2009.

POLANYI, Michael. Personal Knowledge, London: Routledge \& Kegan, 1958.

QUINE, Willard Van Orman. The Web of Belief. New York: Random House, 1970.

RESCHER, Nicholas. The limits of science, Pittsburgh: University of Pittsburgh Press, 1999 (1984).

SAID, Edward. Orientalism. New York: Vintage Books, 1979 (1978).

SANDYWELL, Barry. Reflexivity and the crisis of Western reason. London:

Routledge, 1996.

SHOTTER, John. Goethe and the Refiguring of Intellectual Inquiry: From

"Aboutness"-Thinking to "Withness"- Thinking in Everyday Life. Janus Head: Journal of Interdisciplinary Studies in Literature, v. 8, n. 1, p. 132-158, 2005.

SUÁREZ, José I. \& TOMLINS, Jack E. Mário de Andrade: The Creative Works, Lewisburg, PA: Bucknell University Press, 2000.

SWEDBERG, Richard. Theorizing in sociology and social science: turning to the context of discovery. Theory and Society n. 41, p. 1-40, 2012. 